\author{
dspace.vutbr.cz
}

\title{
Energy considerations in spraying process of a spill-return pressure-swirl atomizer
}

\author{
JEDELSKÝ, J.; JÍCHA, M.
}

Applied Energy

2014, vol. 132, November 2014, pp. 485-495

ISSN: 0306-2619

DOI: https://doi.org/10.1016/j.apenergy.2014.07.042

Accepted manuscript

(C) 2014. This manuscript version is made available under the CC-BY-NC-ND 4.0 license

(http://creativecommons.org/licenses/by-nc-nd/4.0/), doi: https://doi.org/10.1016/j.apenergy.2014.07.042

Final version available from http://www.sciencedirect.com/science/article/pii/s0306261914007247 


\title{
Energy considerations in spraying process of a spill-return pressure- swirl atomizer
}

\author{
Jan Jedelsky ${ }^{*}$ and Miroslav Jicha \\ Faculty of Mechanical Engineering, Brno University of Technology, Technicka 2896/2, 61669 Brno, Czech \\ Republic
}

\begin{abstract}
The work focuses on energy conversion during the internal flow, discharge and formation of the spray from a pressure-swirl (PS) atomizer in the simplex as well as spill-return mode. Individual energy forms are described in general and assessed experimentally for a particular PS atomizer and light heating oil as a medium. The PS spray was observed at various loads to investigate the liquid breakup process and the spray characteristics. Spatially resolved diameters and droplet velocities, measured by means of phase-Doppler anemometry, served for estimation of the energy characteristics in the PS spray.

The input energy given by the potential energy of the supplied liquid partially converts into the kinetic energy (KE) in the swirling ports with hydraulic loss in per cent scale. Most of the pressure drop is associated with rotational motion in the swirl chamber with total conversion efficiency at the exit orifice $\sim 58 \%$. The rest of the input energy ends up as friction loss, leaving room for improvement.

The overall value $\left(I D_{32}\right)$ of the Sauter mean diameter of droplets in the spray, $D_{32}$, varies with pressure drop $\Delta p_{l}$ powered to -0.1 . The radial profiles of $D_{32}$ widen with the increase in spill/feed ratio (SFR), but the $I D_{32}$ remain almost constant within the studied SFR range. The spray KE at closed spill line covers the droplet KE (21-26\%) and that of entrained air (10-13\%), both moderately varying with $\Delta p_{\text {I. }}$. The specific KEs of both the liquid and air markedly drop down with the spill line opening.

Atomization efficiency is less than $0.3 \%$ for the studied range of operation regimes and depends on $\Delta p_{l}$ and SFR. Our results confirm low power demand of simplex PS atomizers, with extra energy consumption in spill mode. Several recommendations are given for PS atomizer innovations and development of new, more efficient, designs meeting more stringent environmental requirements.
\end{abstract}

\section{Keywords}

Pressure-swirl atomizer, Spill-return, Atomization efficiency, Energy conversion, Sauter mean diameter, Spray formation

\section{Introduction}

Atomization of liquids is a process during which bulk liquid is transformed into fragments or small droplets; the process is accompanied with a significant increase in the interfacial area and consumes the energy introduced to the liquid at the atomizer inlet. The nature of the feed energy ${ }^{1}$ determines the atomization process. Thus, from the energy point of view, an atomizer can be considered a device that converts the input energy, $E_{i}$, into the increased surface tension energy of sprayed liquid, $E_{A}$. Effectiveness of the conversion is characterised by the atomization efficiency: $\eta_{a}=E_{A} / E_{i}$. Its knowledge allows comparison of different types of atomizers and improvement of the spray quality. The quality of the atomization process is frequently described using the Sauter mean diameter (SMD or $D_{32}$ ) [1] of the final droplets in the spray; the smaller the SMD the better the spray is. It is crucial namely in combustion applications; the SMD of a sprayed fuel strongly affects the combustion process, namely the stability limits, combustion efficiency and pollutant emission levels. Good atomization quality promotes the fuel evaporation and decreases the demand of ignition energy [2]. A properly designed atomizer is thus a prerequisite for efficient combustion and optimal use of energy resources through proper utilization of the chemical energy contained in expensive fossil liquid fuels.

Bayvel and Orzechowski [3] show all traditional atomizers work with very small $\eta_{a}$, typically below $0.1 \%$, and that any spray quality improvement requires disproportionally more energy as $\eta_{a}$ drops down. For example, a pressure atomizer generating $100 \mu \mathrm{m}$ droplets has $\eta_{a}=0.05-0.07 \%$ and to reduce the diameter to $50 \mu \mathrm{m}$ causes the efficiency to drop to the order of several thousandths per cent. Rivette and Evers [4] calculated atomization

\footnotetext{
${ }^{*}$ Corresponding author. Tel.: +420 541143 266; fax: +420 541143365.

E-mail address: jedelsky@fme.vutbr.cz (J. Jedelsky).

${ }^{1}$ It is either the potential energy of the liquid in pressure atomization, the electric energy for ultrasonic and electrostatic atomizers, or the mechanical power for rotary atomizers etc.
} 
efficiencies of compound pressure nozzles ranging from 0.4 to $1 \%$ according to the injection pressure. They observed that increasing the velocity of the fluid is an increasingly inefficient method of creating the turbulence necessary for drop formation. Dumouchel et al. [5] also studied compound nozzles and found their atomization efficiency in range 0.9-2.6\% depending on their design rather than on injection pressure. Loefler-Mang and Leuckel [6] investigated the atomization process of spill controlled pressure-swirl (PS) atomizers and found remaining surface energy of droplets between 0.1 and $0.4 \%$ of the initial static pressure energy. Petela [7] applied an exergetic approach to the pressure and airblast atomization. He found the exergetic efficiency of the pressure atomization for inlet pressures in the order of $0.1-1 \mathrm{MPa}$ is below $1 \%$ and it decreased with the growth in the inlet pressure. Sovani et al. [8] compared the performance of a conventional pressure injector with an effervescent Diesel injector (DI) designed for fuel injection into Diesel engines. They found the pumping energy required for delivering fuel with their effervescent DI operating at an injection pressure of $18 \mathrm{MPa}$ and $2 \%$ gas to liquid ratio (GLR) is over five times smaller than that required by a conventional DI operating at $150 \mathrm{MPa}$ for comparable $D_{32}$ value. We [9] studied the energy conversion in an effervescent atomizer for inlet pressures of $0.1-0.5 \mathrm{MPa}$ with $2-10 \%$ GLR and shown its $\eta_{a}$ is less than that of PS atomizer for the same spray quality. Lefebvre [10] evaluated the efficiency of airblast atomizers and found it to be 0.007. Several spraying methods, developed for specific purposes, work more efficiently than PS atomization; the roller atomization with $\eta_{a}=30 \%$ and ultrasonic atomization with energy requirement less than $100 \mathrm{~J} / \mathrm{kg}$ of atomized particles [11].

PS atomizers are widely used in industrial and domestic burners, utility boilers [12], gas turbine combustors [13], in aviation engines [14], direct injection gasoline engines [15], rocket engines [13], and many other engineering areas thanks to their simple design, low energy demands and good atomization characteristics required for high quality combustion with minimum emissions. A drawback of the simplex PS nozzles is the poor atomization quality at low flow rates, where inlet pressures are reduced. This disadvantage has been overcome by the spill-return PS nozzles. Above cited works give important information on the atomization characteristics of simplex PS atomizers and other spraying techniques as well but spill-return PS atomizers are only sporadically referred to. A detailed description with an analysis of the entire energy conversion process of simplex and namely spill-return PS atomizers is, to the best of our knowledge, absent in the literature. In this paper, we address some aspects of the energy conversion process during PS atomization. An experimental study of PS atomizer was performed in simplex as well as spillreturn mode with the aim to estimate the individual energy ratios during the internal flow, discharge and formation of the spray. An analysis of the energy processes reveals possibilities for innovative designs of PS atomizer with increased spraying efficiency.

\section{Experimental facility}

The experimental data included in this work were acquired during cold testing of a PS atomizer in the Spray laboratory at the Brno University of Technology. Following paragraphs describe essential experimental equipment used including the atomizer under test, cold test bench with the fluid supply system and PDA system.

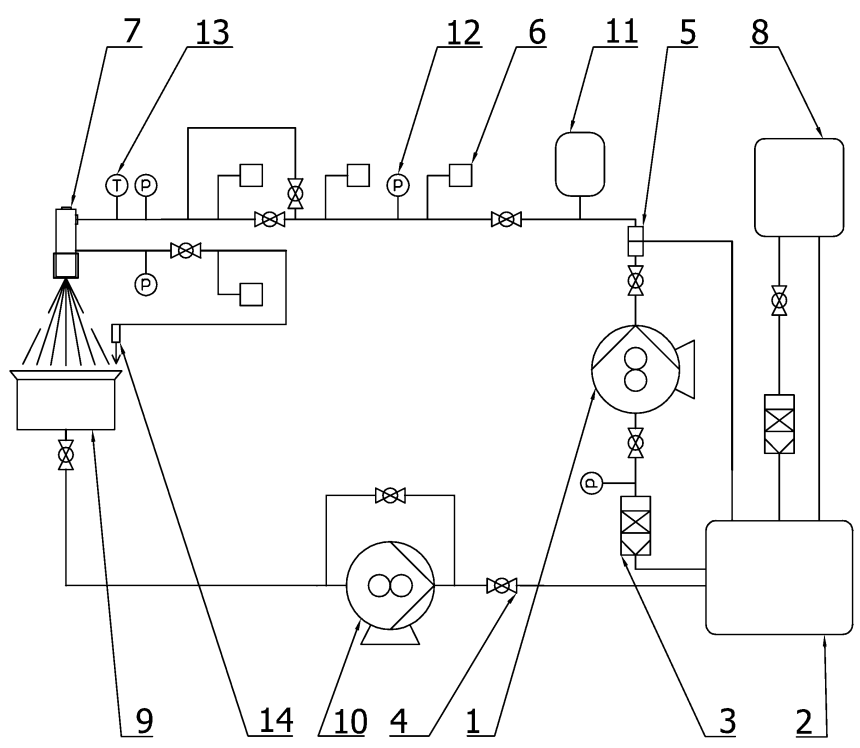

Fig. 1. Schematic layout of the experimental facility. 


\subsection{Cold test bench}

A schematic layout of the test bench is shown in Fig. 1. It consists of a gear feed pump (1) that supplies fuel from a main tank (2) through filters (3), control valves $(4,5)$ and flow meters $(6)$ into the atomizer (7). A chiller (8) controls the fuel temperature hence its viscosity. The spray falls into a collector (9) and then it is returned to the main supply tank by a pump (10). The collector is connected to a fuel mist separator that keeps the spray zone free of aerosol but does not substantially disturb the spray. The fuel piping is equipped with a hydraulic shock absorber (11) placed in front of the atomizer. Flow rate of spill-return atomizers at given inlet pressure $\Delta p_{l}$ is controlled by a regulating valve at its spill return line (14). The feeding and return lines are equipped with flow meters, pressure (12) and temperature (13) readings. Uncertainty in fluid pressure measurements is $16 \mathrm{kPa}$. Uncertainty of the fluid temperature measurements is $0.4^{\circ} \mathrm{C}$. Uncertainty of the volumetric flow rate measurements is $5 \%$ of the measured value. Uncertainty values of the different instruments are taken from the manufacturer's supplied datasheets.

\subsection{Atomizer description and operation}

A spill-return PS atomizer, working originally in a high-power stationary oil burner, was used for this study. The nozzle (Fig. 2) is placed in a body which provides an inlet, distribution and return of fuel and gripping to a 3D computer controlled support. Fuel is fed into a swirl chamber through four tangential ports of a square cross-section. The swirl chamber contains a cylindrical entry part followed by a conical part and exit orifice of small length-todiameter ratio. The spill return line is placed in the nozzle axis at the top cap and opens using a regulating valve.

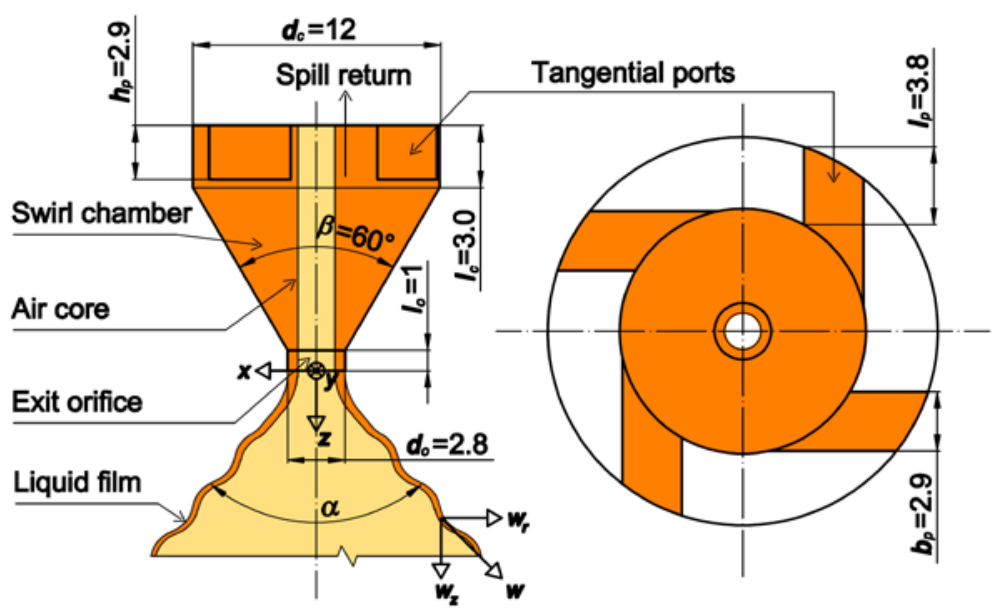

Fig. 2. Schematic layout of the atomizer with main dimensions in millimetres. The coordinate system is identical with that in Fig. 3.

The atomizer was continuously operated with a vertical downward position of the main axis. All tests were done with one batch of light heating oil (LHO) which simulates real hydrocarbon fuel. LHO is suitable testing fluid as it is not as volatile as other primary fuels [16]. It was chosen as the Newtonian model fluid also as its atomizationimportant properties (viscosity, surface tension and density) are close to these of other fuels sprayed with PS atomizers frequently, such as diesel fuel [8, 17], No. 2 heating oil, kerosene [2, 18, 19], petrol [20-22], nonrenewable fossil fuel substitutes (e.g. biodiesel, E10 [23, 24]), crude or residual oil [13] and waste fuels. Physical properties of the LHO at room temperature are: $\sigma=0.0297 \mathrm{~kg} / \mathrm{s}^{2}, \rho_{l}=874 \mathrm{~kg} / \mathrm{m}^{3}, \mu_{l}=0.0185 \mathrm{~kg} /(\mathrm{m} \cdot \mathrm{s}), c_{l}=2400$ $\mathrm{J} /(\mathrm{kg} \cdot \mathrm{K})$. The viscosity was measured using an Ubbelohde viscometer (uncertainty value $7 \%$ ). We used the detach method to measure the surface tension (uncertainty value 5\%), the density was specified in a certified laboratory and the $C_{l}$ value was taken from literature. The temperature of LHO was kept during all tests at $20 \pm 1{ }^{\circ} \mathrm{C}$ to ensure constant physical properties of the liquid. Operational conditions of spill-return atomizer are described by two independent factors: the pressure differential between the nozzle inlet and exit, $\Delta p_{\text {l, }}$ and the spill/feed ratio ${ }^{2}$ (SFR or $\varepsilon)$.

\subsection{Phase-Doppler analyzer}

Time-resolved size and velocity of droplets were measured using a commercial phase-Doppler analyzer (PDA) by Dantec Dynamics. This 1-component classical PDA system is equipped with a standard optics; basic parameters are given in Table 1, and its configuration with the coordinate system is shown in Fig. 3.

\footnotetext{
${ }^{2}$ reciprocal value of the excess liquid coefficient
} 


\section{Table 1}

Configuration of PDA system.

\begin{tabular}{cc}
\hline Parameter & Value \\
\hline Laser & Ar-Ion $300 \mathrm{~mW}$ \\
Wavelength & $514.5 \mathrm{~nm}$ (up to $90 \mathrm{~mW}$ ) \\
Beam waste diameter & $0.82 \mathrm{~mm}$ \\
Transmitting optics & Dantec $58 \mathrm{~N} 10$ \\
Beam separation & $60 \mathrm{~mm}$ \\
Bragg frequency & $40 \mathrm{MHz}$ \\
Front focal length of & $500 \mathrm{~mm}$ \\
transmitting and receiving & \\
optics & Dantec 57X10, three photo- \\
Receiving optics & $67.6^{\circ}$ \\
Scattering angle $\varphi$ & $0.68^{\circ}$ \\
Elevation angle & Parallel (horizontal) \\
Polarization & First-order refraction \\
Scattering mode & Dantec 58N50 \\
Signal processor &
\end{tabular}
8192 particles measured at each point $j$. We found this number of droplets statistically sufficient for estimation of $D_{32}$ in PS sprays; note that other experimenters [25] acquired only 3,000 validated samples while in [26] acquiring 20,000 drops was stated to ensure sufficient statistical reliability of optical measurement results in PS sprays. Three scans in angular positions shifted by $30^{\circ}$ were always performed and resulting $D_{32, j}$ at radial position $r_{j}$ was obtained by averaging the values of the three measurements at a given $r_{j}$. This averaging was necessary as the PS sprays are not perfectly axially symmetrical and also for statistical reasons.

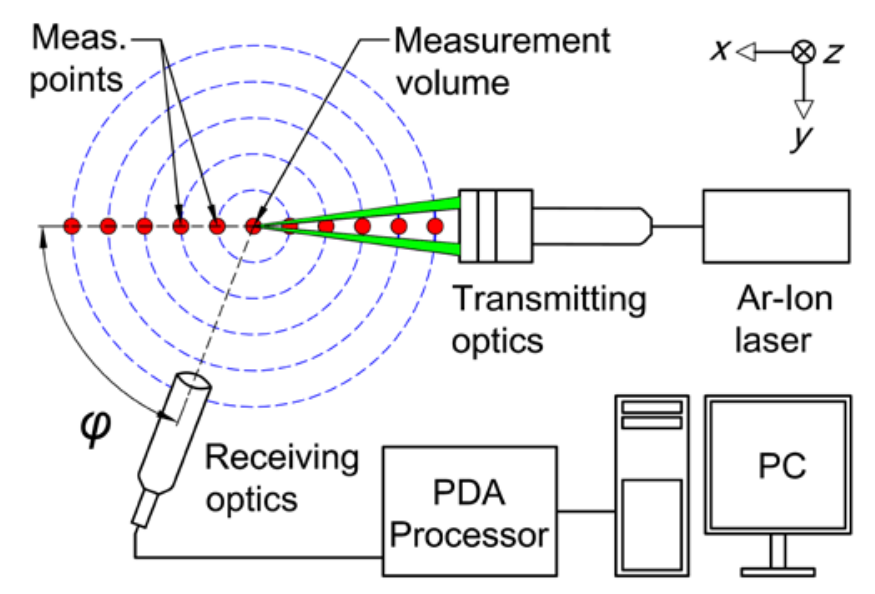

Fig. 3. Set-up for the PDA measurements.

\section{Results and discussion}

Operation of PS atomizer is analysed in a consecutive manner with an emphasis on the energy transfer during the atomization process. The first part deals with internal flow, discharge and sheet formation for a range of atomizer loads. Liquid breakup and spray macrostructure are elucidated with the use of spray photography. PDA is used to provide spatially resolved distributions of droplet characteristics such as diameters and velocities. Efficiency of the spray production is calculated and compared with other atomization techniques.

\subsection{Internal flow, discharge and sheet formation}

The operating principle of PS atomizers relies on the conversion of liquid pressure into kinetic energy (KE) to achieve high relative velocity between the liquid emerging from a nozzle and the surrounding gas. The input energy in non-reacting pressure atomization is predominantly driven by the potential energy of the supplied liquid at a 
pressure drop $\Delta p_{l}$ between the atomizer inlet and exit; all other inlet energy forms can be neglected ${ }^{3}$. The process is considered isothermal with no preheat or cooling. Thermal effects such as vaporization of the atomized liquid (LHO is a non-volatile liquid) or exchange of heat between the discharged liquid and the surrounding air are thus unimportant. A part of the inlet energy is lost during the energy conversion due to friction and dissipation of turbulence; it turns into heat, which amount linearly increases with the inlet pressure. The rise in the liquid temperature between the atomizer inlet and exit $\Delta T=\left(1-\eta_{n}\right) \Delta p_{l} /\left(\rho_{l} c_{l}\right)$, assuming the adiabatic conditions and constant nozzle efficiency $\eta_{n}=0.56$, is $\sim 0.4{ }^{\circ} \mathrm{C}$ for $\Delta p_{l}=2 \mathrm{MPa}$ only. Our measurement of $\Delta T$ (the difference between supply line temperature and temperature in near nozzle spray) using paired thermometers for $\Delta p_{l}=0-2 \mathrm{MPa}$ shown a linear tendency between $\Delta p_{l}$ and $\Delta T$ (with correlation coefficient $R^{2}=0.99$ for the linear fit). The predicted $\Delta T$ values were in whole $\Delta p_{l}$ range systematically by $\sim 20 \%$ higher than the measured ones. This difference can be explained with heat transfer between the liquid and the nozzle surface inside and heat transfer between the liquid and surrounding air outside the atomizer. The linearity between $\Delta p_{l}$ and $\Delta T$ suggests for constant $\eta_{n}$ value, which is analysed bellow and confirmed using other methods.

\subsubsection{Internal flow}

Part of the inlet pressure energy converts into KE in the supply channel and swirling ports; the value is 1\% of the inlet energy independently of the operation pressure. Oil flow in these ports has a laminar character with Reynolds number $\mathrm{Re}_{\mathrm{p}}=316-898$ for the observed range of $\Delta p_{l}=0.2-2 \mathrm{MPa}$. Specific hydraulic loss in rectangular swirling ports, predicted according the Darcy-Weisbach equation with Darcy friction factor $f_{D}=64 / \mathrm{Re}_{\mathrm{p}}$ in duct systems, is:

$$
e_{h p}=\frac{\Delta p_{p}}{\Delta p_{l}} \cong 8 \mu_{l} \sqrt{\frac{n_{p}}{k_{p 1} A_{p}}} k_{p 2}\left(1+k_{p 1}\right)^{2} \frac{w_{p}}{\Delta p_{l}}
$$

where $k_{p 1}=b_{p} / h_{p}, k_{p 2}=l_{p} / b_{p}$ and $A_{p T}=n_{p} h_{p} b_{p}$. Eq. (1) has a minimum for $k_{p 1}=1 / 3$, so swirl ports with $b_{p}=0 . \overline{3} h_{p}$ are to be used to reduce the loss. The $e_{h p}$ is relatively low - in unit per cent scale for our nozzle. The flow velocity and cross-sectional area affect the flow downstream and spray formation, and cannot be simply changed to minimize the loss. Tipler and Wilson [27] recommend the length to width ratio of ports, $k_{p 2}$, should not be less than 1.3, as short slots discharge the liquid in a diffused manner and may result in an uneven spray. Short ports also do not steer the flow tangentially enough. So the port length should be set to the recommended value of $1.3 b_{h}$ but not larger to keep the pressure loss low. The minimum sufficient number of the swirl ports, $n_{p}$, providing homogeneous swirling flow and a uniform spray [28] should be used, as large port number also negatively affects the loss.

The oil enters a swirl chamber in the tangential direction producing strongly vortical flow with an air core in the nozzle centerline. This flow is relatively complex [29] with a dominant swirling velocity component containing vortices of various types [30-33]. Significant part of the remaining pressure drop converts into KE at the exit orifice and partly dissipates due to viscous effects in the liquid and by friction on the inner walls while the surface energy rise due to the establishment of the air core is minor. Hydraulic loss in the cylindrical part of the swirl chamber can be, assuming simple helical flow, very roughly rated as:

$$
\Delta p_{c} \propto 0.5 \rho_{l}^{a+1} \mu_{l}^{-a} d_{c}{ }^{a-1} l_{c} w^{a+2}
$$

where $a$ depends on the character of the flow and for our case, where $\mathrm{Re}_{\mathrm{W}}=2830-8940$ according Walzel [34], $a \cong 0.3$. The chamber loss increases with the chamber length, $l_{c}$, and decreases with its diameter, $d_{c}$. Changing $d_{c}$ complexly affects the spray quality as well as spray cone angle (SCA or $\alpha$ ), so its simple enlargement to reduce the $\Delta p_{c}$ is not applicable. The chamber length should be kept short to minimize frictional loss, however, sufficient length must be provided for the separate jets issuing from the swirl ports to coalesce into a uniform vortex sheet [35]. Other work [36] suggests that higher values of the length/diameter ratio of swirl chamber, $l_{c} / d_{c}$, up to a maximum of 2.75 result in improved atomization.

The total energy loss inside the atomizer is characterised by the nozzle efficiency $\eta_{n}$ and the velocity coefficient $c_{w}{ }^{4}$, where $\eta_{n}=c_{w}^{2}=\rho_{l} w_{o}^{2} / 2 \Delta p_{l}$ is the efficiency of the input energy conversion into KE at the nozzle exit. Using our PDA data for the near nozzle velocity of the liquid phase and approximating the velocity decay curve to the exit orifice, we found $\eta_{n}=0.59$ for $\Delta p_{l}=1 \mathrm{MPa} ; \eta_{n}$ moderately decreases with $\Delta p_{l}$ (see Table 2). Note that other authors [6, 37] report even lower values as $\eta_{n}=0.1-0.4$ while Horvay and Leuckel [38, 39] measured $\eta_{n}=0.42-0.66$

\footnotetext{
${ }^{3} \mathrm{KE}$ of the liquid delivered to the atomizer is $\sim 0.2 \%$ of the inlet pressure energy for inlet pipe diameter of $10 \mathrm{~mm}$, independent of $\Delta p_{l}$. Original surface energy and potential energy term due to gravity (for a height of $0.2 \mathrm{~m}$ ) are less than $0.006 \%$ and $0.9 \%$ respectively at $\Delta p_{l}=0.2 \mathrm{MPa}$, and both of them are inversely proportional to $\Delta p_{l}$. Fluid compressibility contributes negligibly to total energy input for the pressure drops in MPa scale.

${ }^{4}$ It compares real discharge velocity with the theoretical one for an ideal nozzle working with inviscid liquid.
} 
depending on the shape of the convergent part of the swirl chamber and Yule with Chinn [40] found for large PS atomizers $\eta_{n}=0.73-0.86$. The key role of the swirl chamber is to provide a thin liquid film with high-speed injection into still ambient air. The requirement of the highest available velocity (and so the maximised velocity coefficient) is in apparent contradiction with the requirement for the thinnest possible liquid film (which is conditioned by complex internal flow). It explains the wide range of nozzle efficiencies reported by different authors. The internal energy loss, given as $1-\eta_{n}$, is typically $42 \%$. Just a few per cent of this loss belongs to the swirl ports; most of the energy is spent in the swirl chamber so any optimization efforts should target to improvement of the chamber flow.

\subsubsection{Discharge and sheet formation}

The photographic documentation of the PS spray was made to observe the breakup process and to acquire overall information on the spray macrostructure, see Figs. 4 and 5. The liquid flows through the discharge orifice in an annular form and spreads as a conically shaped film, due to conversion of the tangential velocity component into the radial one, increasing its surface and interacting with the ambient air. The exit velocity is proportional to the square root of $\Delta p_{l}$. The initial film thickness at the exit orifice:

$$
t_{o}=\frac{\dot{Q}_{l o}}{\pi d_{o}} \sqrt{\frac{\rho_{l}}{2 \Delta p_{l} \eta_{n}}}
$$

The film envelope widens with the axial distance $z$ from the nozzle exit which causes its thinning into a membrane like form. Assuming simple attenuation of the film, with no surface waving, perforations and agglomeration, its thickness downstream the nozzle is

$$
t(z)=\frac{t_{o} d_{o}}{d_{o}+2 z \cdot \operatorname{tg} \alpha / 2}
$$

The film thickness, at the exit orifice, moderately varies with flow conditions as $t_{o} \propto \operatorname{Re}_{W}^{-0.1}$ (in good agreement with [41, 42]), and it is $\sim 0.5 \mathrm{~mm}$ thick (this value correspond to results in [30, 43] after scaling according to the nozzle size) for $\Delta p_{l}=0.2 \mathrm{MPa}$, which corresponds to the surface energy $e_{A o}$ equal to $0.01 \%$ of the inlet energy. The $e_{A o}$ decreases with $\Delta p_{l}$. This slightly wrapped and waved thin layer of liquid faces a propagation of instabilities within the liquid as well as over the liquid surface, caused by the high slip velocity between the liquid film and the ambient gas.

\section{Table 2}

Atomizer characteristics with spill return line closed.

\begin{tabular}{lllllllllll}
\hline $\begin{array}{l}\Delta p_{l} \\
(\mathrm{MPa})\end{array}$ & $\begin{array}{l}\dot{Q}_{l o} \\
(\mathrm{ml} / \mathrm{s})\end{array}$ & $\begin{array}{l}\eta_{n} \\
(\%)\end{array}$ & $\begin{array}{l}L^{\mathrm{a}} \\
(\mathrm{mm})\end{array}$ & $\begin{array}{l}\mathrm{SCA}^{\mathrm{a}} \\
\left({ }^{\circ}\right)\end{array}$ & $\begin{array}{l}t_{L^{\mathrm{b}}} \\
(\mathrm{mm})\end{array}$ & $\begin{array}{l}I D_{32} \\
(\mu \mathrm{m})\end{array}$ & $\begin{array}{l}e_{A L} \\
(\%)\end{array}$ & $\begin{array}{l}\eta_{a} \\
(\%)\end{array}$ & $\begin{array}{l}e_{k D^{\mathrm{c}}} \\
(\%)\end{array}$ & $\begin{array}{l}e_{k g}{ }^{\mathrm{d}} \\
(\%)\end{array}$ \\
\hline 0.2 & 77.5 & - & 82 & - & - & - & - & - & - & - \\
0.4 & 106 & - & 57 & 41 & 0.04 & - & 0.40 & - & - & - \\
0.6 & 128 & - & 29 & 43 & 0.07 & - & 0.15 & - & - & - \\
0.8 & 145 & - & 15 & 43 & 0.11 & - & 0.07 & - & - & - \\
1.0 & 160 & 58.9 & 10 & 44 & 0.14 & 87.2 & 0.04 & 0.20 & 25.8 & 9.7 \\
1.2 & 174 & 56.8 & 12 & 44 & 0.12 & 85.7 & 0.04 & 0.17 & 22.9 & 9.4 \\
1.4 & 187 & 58.0 & 10 & 44 & 0.13 & 84.1 & 0.03 & 0.15 & 22.8 & 10.4 \\
1.6 & 199 & 55.7 & 10 & 44 & 0.14 & 83.6 & 0.03 & 0.13 & 21.2 & 11.2 \\
1.8 & 210 & 52.9 & 10 & 45 & 0.13 & 82.6 & 0.02 & 0.12 & 21.4 & 12.3 \\
2.0 & 221 & 55.9 & 11 & 45 & 0.13 & 81.4 & 0.02 & 0.11 & 21.1 & 13.5 \\
\hline
\end{tabular}

${ }^{a}$ Based on photographic documentation.

218 b Calculated according Eq. (4).

$219{ }^{c}$ Calculated according Eq. (6) using PDA data.

$220{ }^{\mathrm{d}}$ Calculated according Eq. (7) using PDA data.

The magnitude of the surface irregularities grows up with the distance from the nozzle until it causes ruptures and consequent breakup of the liquid membrane. Only surface wave instabilities were found to initiate the sheet breakup, contrary to [44], where two sheet atomization regimes (perforations and surface waves) were documented. The mean breakup length ${ }^{5}$ was measured using spray photography and is documented in Table 2 together with the relative surface energy at the breakup position, $e_{A L}$. At low $\Delta p_{l}, \sim 0.2 \mathrm{MPa}$, the liquid film shows an onion stage; the surface tension forces dominate and overcome the radial momentum which causes the film to collapse. The film does

\footnotetext{
${ }^{5}$ It is the average length of the liquid sheet measured on the sheet envelope from the exit orifice to the point where the sheet is no continuous any more.
} 
not break up until the collapse point and atomizes poorly afterwards (Fig. 4) with dripping character of the breakup process $^{6}$. The spray shape changes with increasing $\Delta p_{l}$ to a tulip-like one with still inferior atomization. Primary atomization of the entire liquid volume completes at $\Delta p_{l}>0.4 \mathrm{MPa}$ in a large distance from the nozzle exit. With further increase of $\Delta p_{l}$, the atomization improves, and the breakup point approaches the exit orifice due to the increased relative gas-to-liquid velocity. Also, the SCA slightly widens (see Table 2). At common operating pressures, units of $\mathrm{MPa}$, the discharged mass takes a form of fully developed hollow cone spray. Further change of $\Delta p_{l}$ does not significantly affects the SCA any more; its value is practically given by the internal nozzle geometry; this effect was also seen by Mandal et al. [45]. This variable effect of $\Delta p_{l}$, on SCA can be approximated as $S C A \propto \Delta p_{l}^{0.05}$ in reasonable agreement with [37] who for similar nozzle and $\Delta p_{l}$, report $S C A \propto \Delta p_{l}^{0.11}$. Ballester and Dopazo [12] for smaller PS atomizer found $S C A \propto \Delta p_{l}^{0.42}$. Such different trends suggest for sensitivity of the momentum transfer during discharge to internal flow conditions.

Table 3

Atomizer characteristics with varying spill/feed ratio at $\Delta p_{l}=2 \mathrm{MPa}$.

\begin{tabular}{lllllllllll}
\hline$\varepsilon$ & $\begin{array}{l}\dot{Q}_{l o} \\
(\mathrm{ml} / \mathrm{s})\end{array}$ & $\begin{array}{l}\eta_{n} \\
(\%)\end{array}$ & $\begin{array}{l}L^{\mathrm{a}} \\
(\mathrm{mm})\end{array}$ & $\begin{array}{l}\mathrm{SCA}^{\mathrm{a}} \\
\left({ }^{\circ}\right)\end{array}$ & $\begin{array}{l}t_{L^{\mathrm{b}}} \\
(\mathrm{mm})\end{array}$ & $\begin{array}{l}I D_{32} \\
(\mu \mathrm{m})\end{array}$ & $\begin{array}{l}e_{A L} \\
(\%)\end{array}$ & $\begin{array}{l}\eta_{a} \\
(\%)\end{array}$ & $\begin{array}{l}e_{k D}{ }^{\mathrm{c}} \\
(\%)\end{array}$ & $\begin{array}{l}e_{k g}{ }^{\mathrm{d}} \\
(\%)\end{array}$ \\
\hline 0 & 221 & 55.9 & 11 & 45 & 0.13 & 81.4 & 0.024 & 0.11 & 21.1 & 13.5 \\
0.43 & 164 & 34.1 & 11 & 50 & 0.11 & 83.6 & 0.026 & 0.06 & 6.5 & 3.5 \\
0.58 & 140 & 18.6 & 10 & 54 & 0.13 & 84.6 & 0.023 & 0.04 & 3.1 & 1.4 \\
0.69 & 119 & 9.9 & 12 & 59 & 0.13 & 84.7 & 0.024 & 0.03 & 1.2 & 0.8 \\
\hline
\end{tabular}

a, b, c, d The same meaning as in Table 2 .

Opening of the spill valve (Fig. 5) causes a part of the liquid to divert from the swirl chamber to the spill return line. The swirl momentum of the liquid inside the nozzle retains but the flow rate through the exit orifice reduces so the ratio between the axial and the radial velocity downstream the nozzle drops down causing the spray cone to expand markedly as documented in Table 3 and Fig. 5. The observed spray structure and its variation with $\Delta p_{l}$ are in accordance with the findings described in $[2,12,46]$.

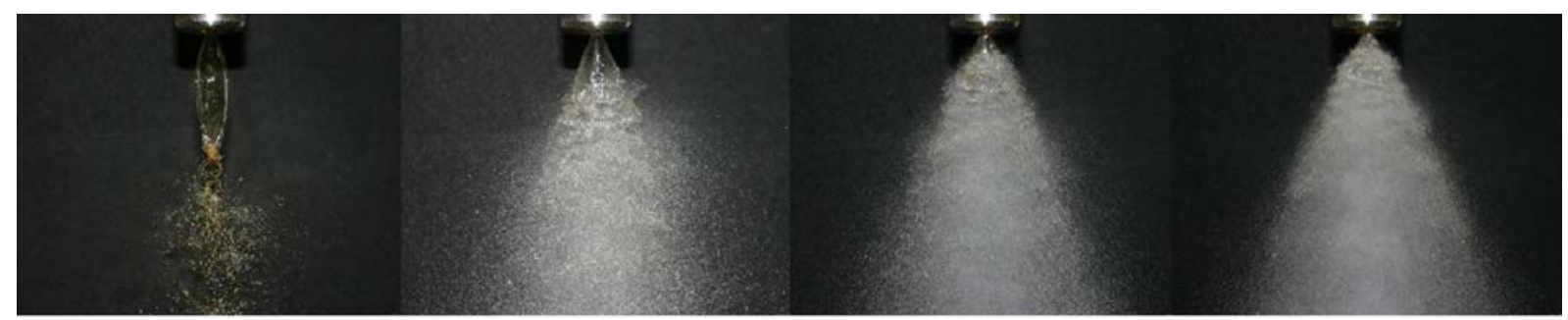

0.2

0.4

0.6

0.8

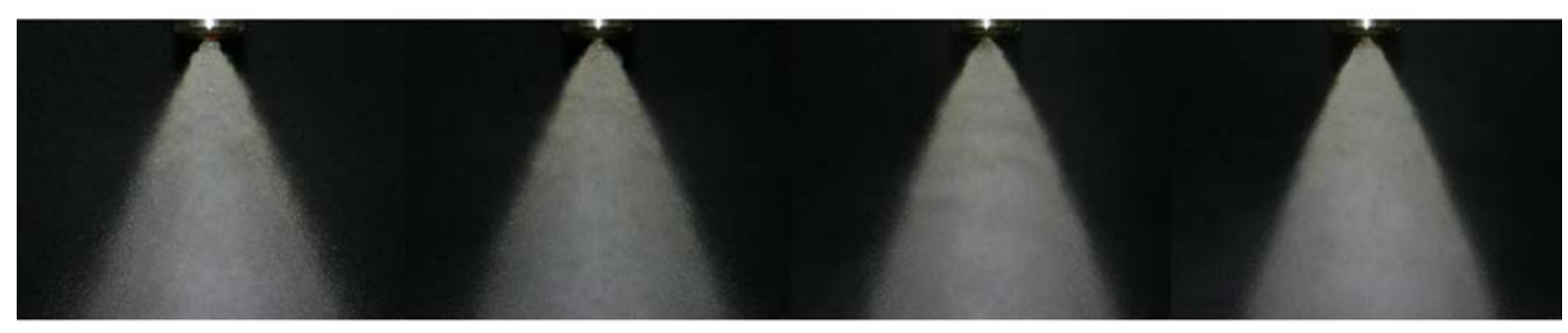

1.0

1.2

1.6

2.0

Fig. 4. Spray structure at varying $\Delta p_{l}(\mathrm{MPa})$, spill return line closed.

\footnotetext{
${ }^{6}$ This poor atomization quality at low loads is retrieved with spill return control.
} 


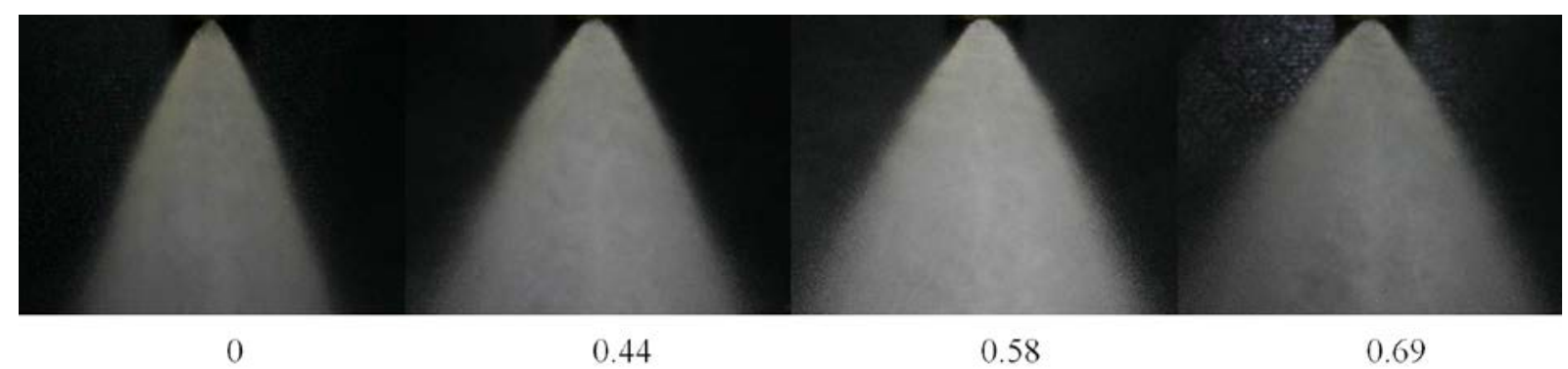

Fig. 5. Spray structure at $\Delta p_{l}=2 \mathrm{MPa}$, SFR varied.

\subsection{Liquid breakup and spray characteristics}

The instabilities in the liquid sheet increase with distance and cause its breakup into ligaments, filaments and finally into drops in the form of a hollow cone spray. Further disintegration of drops into smaller droplets occurs further downstream from the nozzle orifice and is driven by the collision between droplets and the action of aerodynamic forces [3].

The mean droplet size in developed spray varies significantly with the radial position, as illustrated in Fig. 6. The $D_{32}$ is $\sim 40 \mu \mathrm{m}$ in the centreline and increases up to almost $120 \mu \mathrm{m}$ on the spray border at $\Delta p_{l}=1 \mathrm{MPa}$. Drop size larger at the spray edge results from the droplet and gas dynamics in the spray cone and was also found by Yule et al. [40] and others. Increase in $\Delta p_{l}$ leads to a reduction of the size at radial distances $r>15 \mathrm{~mm}$. The opposite trend near the centreline can be explained by enhanced mixing at greater pressures and transfer of larger droplets into the area. However, the spray in $r<20 \mathrm{~mm}$ is of low importance as it contains less than $3 \%$ of the total liquid mass in all inspected regimes. Small droplets with $D_{32}<60 \mu \mathrm{m}$ fill the central part of the spray cone as they are dislocated there from the main stream by the air movement. 80\% of liquid mass is placed within $r=30-50$ mm and large (heavy) droplets are formed in the outer part of the spray.

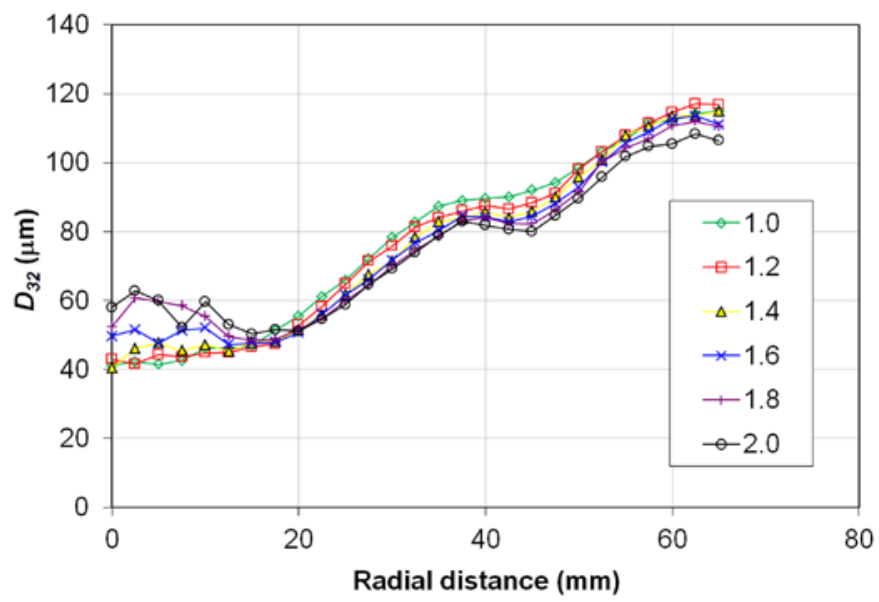

Fig. 6. Radial distribution of $D_{32}$ at varying $\Delta p_{l}(\mathrm{MPa}), z=100 \mathrm{~mm}$, return line closed.

To characterise this wide size range of droplets in the radial profile with a unique parameter we introduce an integral Sauter mean diameter, $I D_{32}$, calculated according Eq. (A.2) of the Appendix. Table 2 shows that $I D_{32}$ monotonically decreases with $\Delta p_{l}$ as expected and in accordance with published data. The trend can be approximated by:

$$
I D_{32} \propto \Delta p_{l}^{-b}
$$

where $b=0.10$ with correlation coefficient $R^{2}=0.99$. By doubling the inlet pressure, $I D_{32}$ drops by $7 \%$. Other authors $[13,47,48]$ who investigated the relation between $D_{32}$ and $\Delta p_{l}$, refer $b=0.23-0.33$ (reported here after a correction for the effect of the pressure on the flow rate, as flow rate is considered an independent factor in these works) for similar PS atomizers and operation conditions. This large difference can be partly explained by different measurement methods used, as described in the Appendix and proposed in [49] or by experimental conditions. Also, rheological properties of the atomized liquid play an important role (described in Section 3.4 and [50]). Other reason can be the range of radial positions where they measured the $D_{32}$. For example, our data give $D_{32} \propto \Delta p_{l}^{-0.17}$ at the position of the maximum liquid flux ( $r=42.5 \mathrm{~mm}$ ). Different trends would be found for other droplet statistics such 
as arithmetic mean diameter, $D_{10}$, or mass mean diameter, $D_{v 0.5}$, due to the difference in size distributions. Note that the $I D_{32}$ at $z=100 \mathrm{~mm}$, where the breakup is completed (see explanation in Section 3.3), is in a constant ratio to the sheet thickness, estimated according Eq. (4) at the characteristic breakup position, for the whole range of the $\Delta p_{l}$ as shown in Table 2: $t_{L} \cong 1.6 I D_{32}$. We, therefore, deduce that the variation of droplet size with $\Delta p_{l}$ change depends on the effect of $\Delta p_{l}$ on the relative liquid-to-air velocity rather than on the effect of $\Delta p_{l}$ on the sheet formation. Using our formula $I D_{32} \propto \Delta p_{l}^{-0.1}$, we estimate that an improvement in nozzle efficiency by 10 percentage points, due to eventual chamber redesign, would reduce the $I D_{32}$ by $1.6 \%$. A chamber modification producing a sheet with reduced thickness could have a stronger impact.

The $D_{32}$ profiles for the cases of the return line opening (Fig. 7) seem to drop down with the increase in SFR but these curves rather shift to greater radial positions with the spray widening (documented by the spray photography in Fig. 5 above) as it is also suggested by the almost constant $I D_{32}$ values in Table 3 within the studied SFR range. The negligible effect of SFR on the $I D_{32}$ is in agreement with [51].

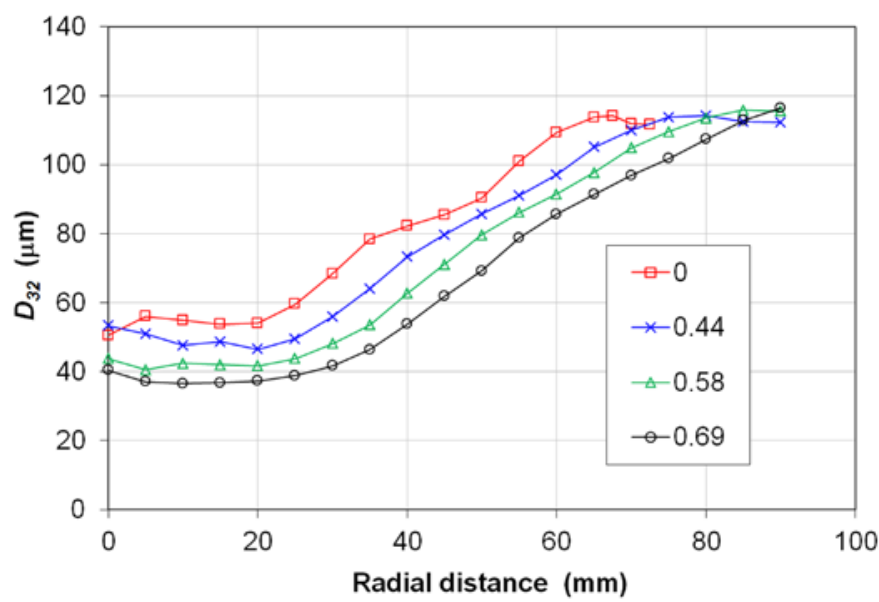

Fig. 7. Radial distribution of $D_{32}$ at $\Delta p_{l}=2 \mathrm{MPa}$, SFR varied, $z=100 \mathrm{~mm}$.

\subsection{Kinetic energy of droplets and air}

The KE of the spray contains the energy of moving droplets and the energy of the entrained mass of ambient air. These energies can be estimated separately using the PDA data. The specific KE of liquid (droplets):

$$
e_{k D}=\frac{E_{k D}}{E_{i}}=(1-\varepsilon) \frac{\rho_{l}}{2 \Delta p_{l}} \sum_{j=1}^{m} r_{j} \sum_{i=1}^{n_{j}} D_{i j}^{3} w_{D i j}^{2} / \sum_{j=1}^{m} r_{j} \sum_{i=1}^{n_{j}} D_{i j}^{3}
$$

where $D_{i j}$ is the diameter of an individual droplet $i$ at the radial distance from the atomizer axis $r_{j}$. Its velocity, $w_{D i j}$, was estimated by $w_{D i j}=w_{z D i j} \sqrt{z^{2}+r_{j}^{2}} / z$ with the tangential velocity component neglected (it is typically one order of magnitude lower than axial component $w_{z D i j}$ ). An axially symmetrical spray and equidistant sampling distance $\Delta r_{j}=r_{j}-r_{j-1}$ were assumed.

Specific KE of the surrounding air entrained by the sprayed liquid:

$$
e_{k g}=(1-\varepsilon) \frac{\pi \rho_{g}}{\Delta p_{l} \dot{Q}_{l}} \sum_{j=1}^{m} \Delta r_{j} r_{j} w_{g j}^{3}
$$

where the mean air velocity at position $j$ is calculated as $w_{g j}=\frac{1}{n_{j}} \sum_{i=1}^{n_{j}} w_{z D i j}$, using the individual velocity of droplets, $w_{z D i j}$, as an estimate of the local air velocity; only droplets with low Stokes number, typically $<0.2$, which are assumed to follow the flow field well, are included. The smallest, often satellite, droplets were not taken into account.

Individual velocities estimated using PDA in position $100 \mathrm{~mm}$ downstream the exit orifice at $\Delta p_{l}=1 \mathrm{MPa}$ and spill return line closed are shown in Fig. 8. The difference between mean velocity of liquid mass $w_{l j}=\left(\sum_{i=1}^{n_{j}} D_{i j}^{3} w_{D i j}^{2} / \sum_{i=1}^{n_{j}} D_{i j}^{3}\right)^{1 / 2}$ and mean velocity of entrained air, $\Delta w_{j}=w_{l j}-w_{g j}$, strongly varies with $r_{j}$. It is low in the area near the nozzle axis, which is occupied mainly by small droplets, already decelerated by the ambient air while large velocity difference remain in $r_{j}>30 \mathrm{~mm}$ where the spray is formed by large droplets. The ratio between 
the gas phase Weber number and critical Weber number, calculated for droplet diameter $D_{v 0.98 j}$ at individual positions $j$, is typically 0.1 or less which means the secondary breakup in the axial distance $100 \mathrm{~mm}$ is completed.

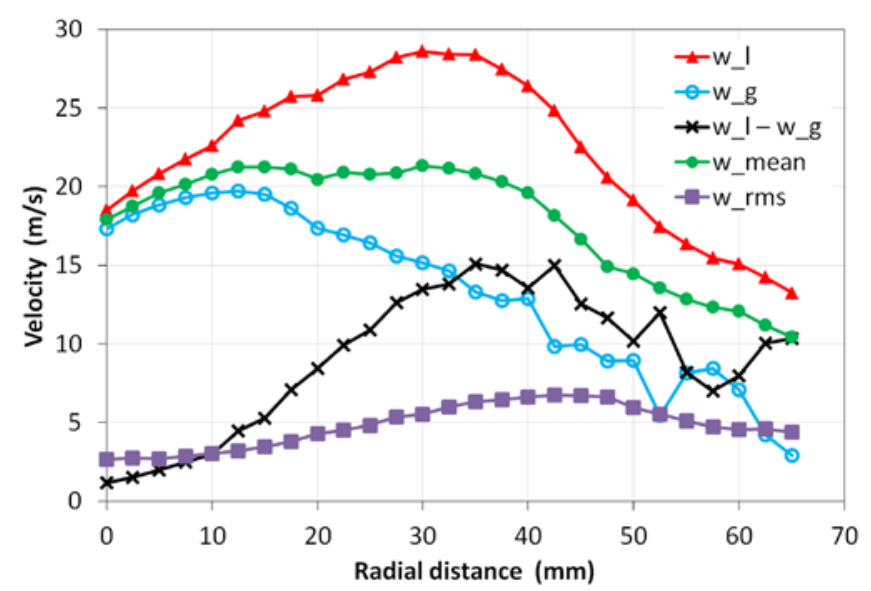

Fig. 8. Radial distributions of individual axial velocities at $\Delta p_{l}=1 \mathrm{MPa}$, spill return line closed, $z=100 \mathrm{~mm} ; w_{g}=$ gas, $w_{l}=$ liquid, $w_{\text {mean }}=$ mean (for all droplets in the position), $w_{r m s}=$ root-mean-square velocity, $w_{l}-w_{g}=$ liquid to gas velocity difference.

Typical radial distribution of cumulative KE of liquid and gas phases in the spray are shown in Fig. 9. The liquid $\mathrm{KE}$ is concentrated in off-axis area; it reaches $50 \%$ of its total value in $r_{j}=41 \mathrm{~mm}$ while for gas it is $25 \mathrm{~mm}$ at $\Delta p_{l}=1 \mathrm{MPa}$. The droplets keep $\sim 26 \%$ of the inlet energy at this regime (Table 2). This value slightly drops down with $\Delta p_{l}$ increase as the transfer of KE from liquid into air gets more intense with increasing contact area of fine droplets and with widened SCA. The entrained air contains $10-13 \%$ of the inlet energy with the opposite trend compared to the liquid phase due to the increased energy transfer.

The total KE contained in the spray $e_{k D}+e_{k g}=32-35 \%$ in agreement with [6]; it is almost independent on $\Delta p_{l}$., which results from relatively constant $\eta_{n}$ and other energy values. It is by 19-25 percentage points lower than the KE at the nozzle exit, represented by $\eta_{n}$. This energy gap can be attributed to the dissipation within the flow and during mixing of gas with the liquid phase, partially also to turbulent, swirl and vortical air motion ${ }^{7}$ (for its importance compare the rms with the mean velocity in Fig. 8) and entrained air flow outside the measurement boundaries. Minor part of this energy gap is attributed to the interfacial energy increase.

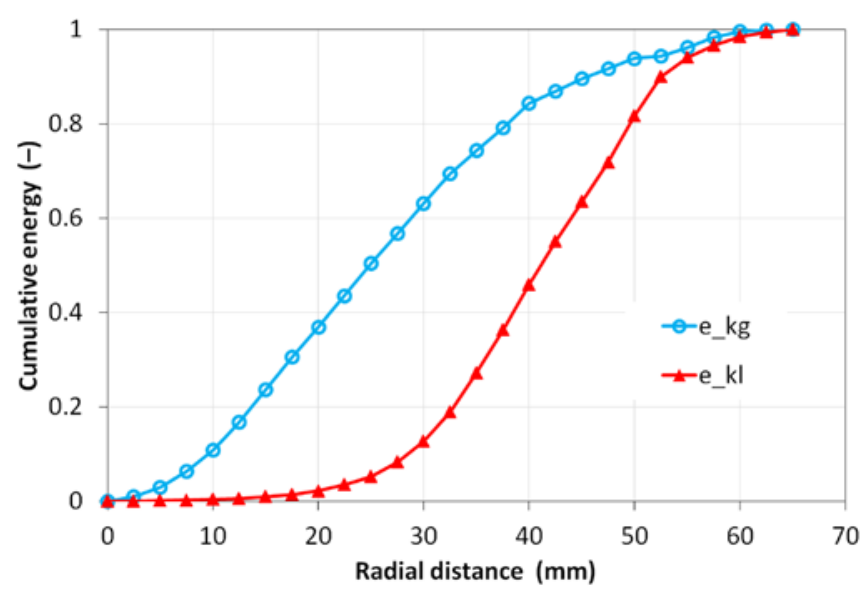

Fig. 9. Radial distributions of gas and liquid KEs in the spray (cumulative values normalised to their maximum) at $\Delta p_{l}=1 \mathrm{MPa}$, spill return line closed, $z=100 \mathrm{~mm}$. 
The specific KEs of both the liquid and the entrained air markedly drop down with the opening of the spill return line as only a fraction of the pumped liquid ends in the spray (see Table 3). The reduction of the total KE with SFR increase is however much faster than the spilled out liquid quantity could simply explain. Changing the discharged fraction $(1-\varepsilon)$ from 0 to $31 \%$ the total KE drops to $6 \%$ of its initial value (when spill line closed). We assume that the liquid phase dispersed to the larger area (larger SCA, see Table 3) interacts more intensively with the surrounding air thus transferring there higher fraction of its original KE.

The spatial distribution of KE in the spray and variation of the KE contained in liquid and gas phases with operation conditions will have significant consequences in combustion application as it controls the fuel supply into the combustion zone as well as fuel-air interaction and the mixture preparation.

\subsection{Atomization efficiency}

The input energy available for the atomization process is represented by the potential energy of the supplied liquid at the pressure drop $\Delta p_{l}$ between the atomizer inlet and exit: $E_{i}=V_{l} \Delta p_{l}$. This energy, as shown above, converts into the KE of liquid, partly dissipates due to viscous effects inside the atomizer and the momentum delivered to the surrounding air. Only small portion of the supplied energy ends in the surface energy of the droplets (and eventually their remaining KE) at the point of interest and can be considered as the effect of the spraying process. The amount of liquid discharged by spill-return nozzles, $V_{l o}$, is only a fraction of the totally supplied liquid, $V_{l i}$, as the other part, $V_{l s}$, is spilled out. The energy which runs away with the spilled amount is considered lost.

The atomization process represents disintegration of bulk liquid into fine droplets, and it is associated with enormous increase of the liquid-air interfacial area ${ }^{8}$. The final interfacial area of a droplet system of a volume $V_{\text {lo }}$ is $A=6 V_{l o} I D_{20}^{2} / I D_{30}^{3}$, where $I D_{20}$ and $I D_{30}$ are representative surface and volume diameters respectively of the final droplets (see Eq. (A.1) in the Appendix) and the ratio $I D_{30}^{3} / I D_{20}^{2}$ corresponds to the overall Sauter mean diameter, $I D_{32}$, as defined in Eq. (A.2) of the Appendix. The corresponding surface energy increase ${ }^{9}$ reads $E_{A}=A \sigma$.

The surface energy increase divided by the inlet energy equals to the efficiency of the atomization process:

$$
e_{A}=\eta_{a}=\frac{E_{A}}{E_{i}}=\frac{6 V_{l o} \sigma / I D_{32}}{V_{l} \Delta p_{l}}=\frac{6 \sigma(1-\varepsilon)}{\Delta p_{l} I D_{32}}
$$

This formula agrees for $\varepsilon=0$ with the equation for exergetic efficiency by [7]. It shows that the efficiency is directly related to $1 / I D_{32}$, so SMD is a measure of the effectiveness of the atomization process for given liquid (determined by $\sigma)$ and for given operation conditions $\left(\Delta p_{l}, \varepsilon\right)$. The remaining $\mathrm{KE}$ can be eventually added to the normalised surface energy of the droplets (efficiency of the atomization process) to represent an expanded (total) effect of the atomization process in the point of interest: $\eta_{a}^{\prime}=\eta_{a}+e_{k D}+e_{k g}$.

The atomization efficiency, shown in Fig. 10, left and Table 2 is less than $0.3 \%$ for the studied range of operation regimes, in accordance with [3,6]. As suggested by the logarithmic scale of the plot, there is approximately an inverse logarithmic tendency of the $\eta_{a}$ with the pressure drop for spill line closed, so $\eta_{a} \propto \exp \left(-\Delta p_{l}\right)$. The decrease in atomization efficiency, related with requirement of small droplets in pressure atomization, was also found by Petela [7], Rivette and Evers [4] and Michalek et al. [52]. The atomizer is increasingly inefficient with the spill line opening (Fig. 10, right and Table 3); the efficiency depends on the output flow rate as $\eta_{a} \propto \dot{Q}_{l o}^{2}$. It is due to the inlet energy fraction being lost in the spilled liquid; the effect of $I D_{32}$ is weak as it remains almost constant with the spill line opening. Internally mixed twin-fluid atomizers, for comparison, based on our results [9, 53] work with $\eta_{a} \propto \dot{Q}_{l o}^{1.8}$ when the flow rate is controlled by GLR change at fixed $\Delta p_{l}$, so their efficiency decreases less markedly. Currently known PS atomizer designs, such as duplex, dual-orifice or variablegeometry [3, 35], solve this weakness but suffer from other shortcomings so a new conception to improve the flow control mechanism of PS atomizers is desired.

Based on the results in Fig. 10 the effect of pressure drop and the SFR can be empirically approximated by

$$
\eta_{a}=0.37(1-\varepsilon) \exp \left(-0.63 \Delta p_{l}\right)(\%,-, \mathrm{MPa})
$$

or using the often reported correlation in Eq. (5):

$$
\eta_{a}=0.204(1-\varepsilon) \Delta p_{l}^{-0.9}
$$

Both equations (9) and (10) fit the experimental data with an error less than $4 \%$.

\footnotetext{
${ }^{8}$ For example a breakup of a liquid sphere with $10 \mathrm{~mm}$ in diameter into 100 micron droplets represents 100 times increase in the interfacial area.

${ }^{9}$ The original surface energy of bulk liquid is neglected.
} 


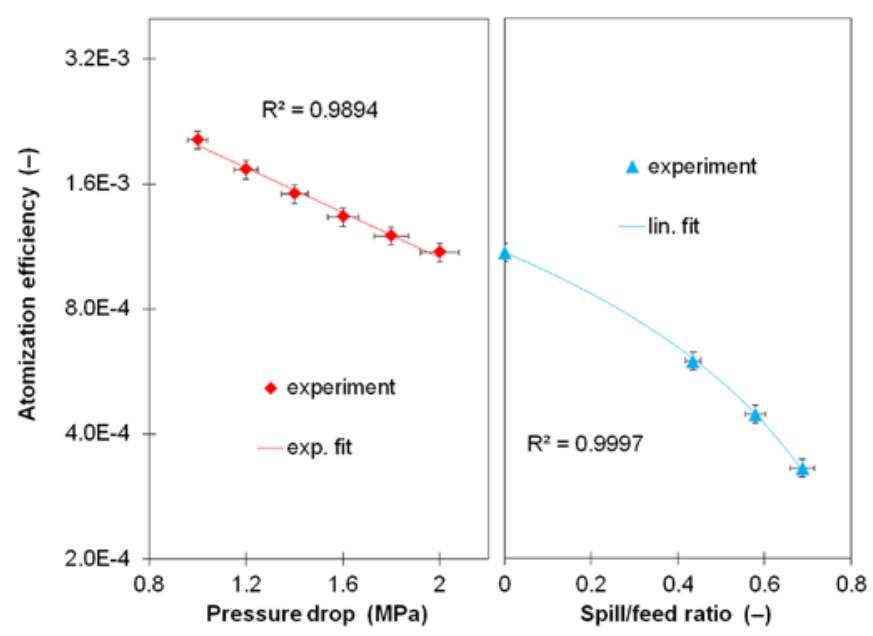

Fig. 10. Atomization efficiency at variable $\Delta p_{l}$ with spill return line closed (left) and at variable SFR for $\Delta p_{l}=2 \mathrm{MPa}$ (right). The fitting curves are provided with $4 \%$ error bars and with correlation coefficient $R^{2}$.

Results given in Fig. 10 are in good agreement with findings of others. Loefler-Mang and Leuckel [6] obtained $\eta_{a}=0.1-0.4 \%$ for spill controlled PS atomizers. Petela [7] found exergetic efficiency of pressure atomizers in the range $0.08-0.24 \%$ for pressure drops between 0.8 and $2 \mathrm{MPa}$ and noted a decrease of the efficiency with the pressure drop.

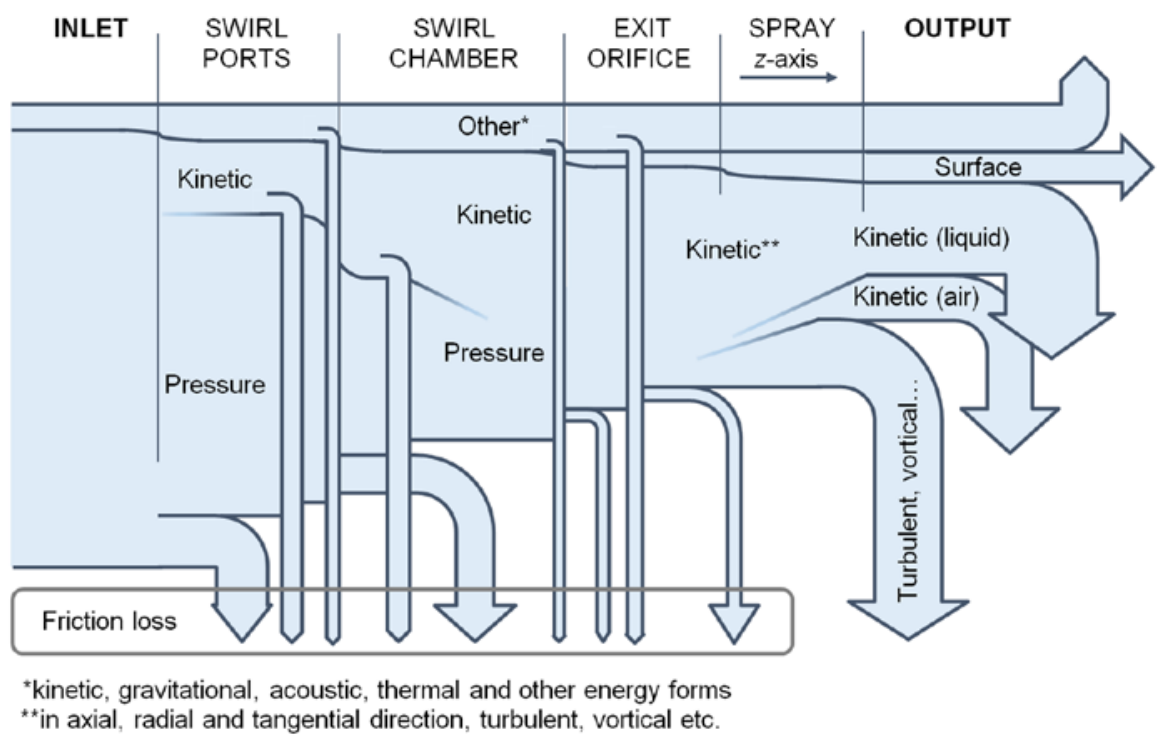

Fig. 11. Sankey diagram for energy balance of the atomization process; the energy flux proportions are illustrative, approximately corresponding to the case with SFR $=0$, not to precise scale.

Two forces act against the liquid disintegration: surface tension, included in the Eq. (8), and viscosity. The effect of viscous forces depends on the atomization route. The relative importance of viscous and surface tension forces can be estimated by the ratio of the liquid phase Weber and Reynolds numbers at the nozzle exit [54]: $W e_{l o} / \operatorname{Re}_{l o}=w_{l o} \mu_{l} / \sigma$. This ratio increases for LHO from 23 to 31.5 when $\Delta p_{l}$ changes from 1 to $2 \mathrm{MPa}$. Its value, much larger than unity, suggests the dominance of viscous over surface tension forces during the spray formation at high velocity. It partly explains the strong negative effect of $\Delta p_{l}$ on $\eta_{a}$. The requirement of small droplets, conditioned with high discharge velocity, thus naturally leads atomization efficiency to drop down. It implies a task to optimize the nozzle design for the best combination of the drop size reducing factors: high discharge velocity, thin liquid sheet and high discharge liquid turbulence. Note, for comparison with other liquids, and namely fuels frequently atomized with PS atomizers, that $W e_{l o} / \operatorname{Re}_{l o}$ for the same atomizer operated at $\Delta p_{l}=2 \mathrm{MPa}$ with water 
(usable e.g. for dust emission control [55] or spray cooling [56, 57]), petrol (internal combustion engines [15, 2022]), ethanol (used around the world commonly in fuel blends for internal combustion engines [58]), diesel fuel (regular automotive fuel [8, 16, 17]), kerosene (aviation fuel [14]) and heavy fuel oil (gas turbine engines [13], utility boilers [12], heavy engines) would be $0.6,1.3,2.8,5.6,40.4$ and 1184 respectively. Liquids of lower $W_{l_{l o}} / \mathrm{Re}_{l o}$ would give higher $\eta_{a}$ as the viscous resistance to the deformation and desintegration will consume smaller fraction of the inlet energy.

The energy theoretically required for atomization of a unit mass $E_{A} / m_{l}=6 \sigma / \rho_{l} I D_{32}=e_{a} \Delta p / \rho_{l}(1-\varepsilon)$ is in our case $\sim 2.4 \mathrm{~J} / \mathrm{kg}$, regardless of $\Delta p_{l}$. The really consumed energy $E_{i} / m_{l}=\Delta p_{l} / \rho_{l}(1-\varepsilon)=E_{A} / e_{a} m_{l}$ is 1000 times greater than the theoretical requirement. A Sankey diagram (Fig. 11) visualizes the energy transfers between individual processes. Mutual energy transformations take place during the spray formation but are only partially depicted for the sake of clarity.

405

406

407

408

409

410

411

412

413

414

415

416

417

418

419

420

421

422

423

424

425

\section{Conclusions}

A PS atomizer was studied in simplex as well as spill-return mode with the aim to estimate individual energy ratios during the internal flow, discharge and formation of the spray. Key results were compared with available literature data and disparities, found in some cases, were explained. The most significant findings are as follows.

- The input energy in pressure atomization is given by the potential energy of the supplied liquid at a pressure drop between the atomizer inlet and exit, with neglecting effect of other energy inputs. A part of this pressure energy converts into the KE in the swirling ports with hydraulic loss in per cent scale. Significant part of the remaining pressure drop (58\%) turns into the KE inside the swirl chamber. Main part of the energy loss (due to viscous effects inside the liquid and friction on the inner walls) attributes to the swirl chamber; it ends in liquid heating by several tenths of a degree Celsius and suggests a potential for improvements.

- Wide droplet size variation within the radial profile in spray was found and attributed to the droplet and gas dynamics. To characterise such wide size range with a unique parameter we introduce an integral Sauter mean diameter, $I D_{32}$. The $I D_{32}$ monotonically decreases with $\Delta p_{l}$ as $I D_{32} \propto \Delta p_{l}^{-0.1}$ and it is in a constant ratio to the sheet thickness at its breakup position. The radial profiles of $D_{32}$ widen with spill line opening, but the $I D_{32}$ remain almost constant within the studied SFR range.

- The KE of the spray at a closed spill line, 32-35\% of the inlet energy, covers the droplet KE (21-26\%) and KE of entrained air (10-13\%); it moderately varies with $\Delta p_{l}$ as energy transfer between droplets and air depends on the contact area of droplets. The spray KE is by 19-25 percentage points lower than the KE at the nozzle exit. This gap resides in the KE dissipation, turbulent and vortical air motion and interfacial energy increase in a small amount. The specific KEs of both the liquid and air markedly drop down with the spill line opening as only a fraction of the liquid pumped ends in the spray.

- The efficiency of the atomization process depends on the pressure drop and SFR as $\eta_{a}=0.0685(1-\varepsilon) \sigma \Delta p_{l}^{-0.9}$ so it declines with increases in $\Delta p_{l}$ and SFR, being less than $0.3 \%$ for the studied range of operation regimes. The drop in $\eta_{a}$ with $\Delta p_{l}$ suggests for quantitative change (reduction) in the energy transfer during spray formation so the disruptive forces act less effectively against the consolidating ones. We explain it with increasing effect of the viscosity compared to the surface tension when discharge velocity increases. Deeper analysis of the atomization process is required to find ways for more efficient breakup process at high pressures; optimum combination of the drop size reducing factors (high discharge velocity, thin liquid sheet and high discharge liquid turbulence) is to be found.

- The main advantages of spill-return atomizers in comparison with the simplex ones, as easy flow rate control with very large turn-down ratio and good atomization for very low flow rates, are at the expense of high energy consumption for the liquid pumping, represented with the $(1-\varepsilon)$ term, and of significant spray angle widening during the reduction from the nominal to minimal flow rate. Duplex design, swirl port switching or variable ports, control mechanism alternates of the spill function, however face other drawbacks. So after long usage of spill-return nozzles an advanced control mechanism invention is advisable.

- $\quad$ Several recommendations result from our findings for the nozzle design: optimum width to height ratio of swirl ports is $1 / 3$, the minimum number of the swirl ports providing homogeneous swirling flow and uniform spray to be used, the length to width ratio of ports should be as small as possible, but minimum about 1.3. Energy loss in the swirl chamber is dominant so future investigations should focus to understand better the chamber flow and optimize the nozzle geometry to increase the nozzle efficiency (maximization of the output velocity) and reduce the sheet thickness at the nozzle exit.

PS atomizers proved to be competitive with other atomizer types in the long term due to their simple design, large turn-down ratio and good atomization characteristics. Our results show their atomization efficiency is comparable with effervescent or compound and better than that of airblast or plain orifice atomizers; however today requirements for energy processes optimization and optimal use of energy resources require innovative designs of this energy conversion device. 


\section{Acknowledgements}

Authors acknowledge financial support from project No. P101/11/1264 funded by the Czech Science Foundation and NETME Centre, regional R\&D centre built with the financial support from the Operational Programme "Research and Development for Innovations" within the project "NETME Centre (New Technologies for Mechanical Engineering)”, Reg. No. CZ.1.05/2.1.00/01.0002 and, in the follow-up sustainability stage, supported through NETME CENTRE PLUS (LO1202) by financial means from the Ministry of Education, Youth and Sports under the "National Sustainability Programme I".

\section{Nomenclature}

A interfacial area, cross-sectional area

$\left(\mathrm{m}^{2}\right)$

$a, b$ coefficients in Eqs. (2) and (5)

(-)

$b \quad$ width

c specific heat capacity

$c_{w} \quad$ velocity coefficient

$D$ droplet diameter

$D_{32}$ Sauter mean diameter, SMD

$(\mathrm{J} /(\mathrm{kg} \cdot \mathrm{K}))$

(-)

$(\mu \mathrm{m})$

d diameter

$(\mu \mathrm{m})$

E energy

(m)

$e \quad$ energy, represented as percentages of the total input energy, specific energy

(J)

$f_{D} \quad$ Darcy friction factor

$h$ height

ID integral (overall) droplet diameter

$(\%,-)$

$(-)$

(m)

$k_{p 1} \quad$ width to length ratio of swirl ports

$(\mu \mathrm{m})$

$k_{p 2} \quad$ length to width ratio of swirl ports

$(-)$

$(-)$

(mm)

$L \quad$ breakup length

l length

(m)

$m$ mass

$n$ number

$(-)$

$\dot{Q} \quad$ volumetric flow rate $\mathrm{ml} / \mathrm{s}$ )

$\operatorname{Re}_{\mathrm{W}}$ Reynolds number according Walzel [34] $\left(=\left(2 \rho_{l} \Delta p_{l}\right)^{0.5} d_{o} / \mu_{l}\right)$

$r \quad$ radial distance from atomizer axis

$T$ thermodynamic temperature

$t$ film thickness

$V \quad$ volume

We Weber number, $\left(W e_{g}=\rho_{g}\left(w_{l}-w_{g}\right)^{2} D / \sigma\right)$

$w \quad$ velocity

$x, y, z$ Cartesian coordinates $(z=$ axial distance)

\section{Greek characters}

$\alpha \quad$ spray cone angle, SCA

$\Delta p_{l} \quad$ pressure differential between the atomizer inlet and exit

$\varepsilon \quad$ spill/feed ratio, SFR, $\left(=V_{l s} / V_{l i}\right)$ according [6]

$\eta_{a} \quad$ atomization efficiency

$\eta_{n} \quad$ nozzle efficiency

$\mu \quad$ dynamic viscosity

$\rho$ density

$\sigma \quad$ liquid/gas surface tension

$(-)$

$(\%,-)$

$(\%,-)$ $(\mathrm{kg} /(\mathrm{m} \cdot \mathrm{s}))$ $\left(\mathrm{kg} / \mathrm{m}^{3}\right)$ $\left(\mathrm{kg} / \mathrm{s}^{2}\right)$

Subscripts

A surface

C swirl chamber

D droplet

$g$ gas, ambient air

$i$ inlet, index number

$j \quad$ index of measurement position

$k \quad$ kinetic (energy)

$L$ in the breakup distance

l atomized liquid (light heating oil, LHO) 
$S \quad$ spill-return

\section{References}

1. Jakobs, T., N. Djordjevic, S. Fleck, M. Mancini, R. Weber and T. Kolb, Gasification of high viscous slurry R\&D on atomization and numerical simulation. Applied Energy, 2012. 93(0): p. 449-456.

2. Lefebvre, A.H. and D.R. Ballal, Gas turbine combustion - alternative fuels and emissions. 2010, Taylor \& Francis,: Boca Raton. p. 1 online resource (xix, 537 p.).

3. Bayvel, L. and Z. Orzechowski, Liquid Atomization. 1993: Taylor \& Francis Inc.

4. Rivette, S.M., Compound port fuel injector nozzle droplet sizes and spray patterns. 1996.

5. Dumouchel, C., J. Cousin, and K.l. Triballier, On the role of the liquid flow characteristics on low-Webernumber atomization processes. Experiments in Fluids, 2005. 38(5): p. 637-647.

6. Loffler-Mang, M. and W. Leuckel, Atomization with Spill-Controled Swirl Pressure-Jet Nozzles. ICLASS-91, Gaithersburg, MD, USA, 1991: p. 431-440.

7. Petela, R., EXERGETIC ANALYSIS OF ATOMIZATION PROCESS OF LIQUID. Fuel, 1984. 63(3): p. 419-422.

8. Sovani, S.D., J.D. Crofts, P.E. Sojka, J.P. Gore and W.A. Eckerle, Structure and steady-state spray performance of an effervescent diesel injector. Fuel, 2005. 84(12-13): p. 1503-1514.

9. Jedelsky, J. and M. Jicha, Energy conversion during effervescent atomization. Fuel, 2013. 111: p. 836-844.

10. Lefebvre, A.H., ENERGY CONSIDERATIONS IN TWIN-FLUID ATOMIZATION. Journal of Engineering for Gas Turbines and Power-Transactions of the Asme, 1992. 114(1): p. 89-96.

11. Liu, H., Science and engineering of droplets : fundamentals and applications. 2000, Park Ridge, N.J. Norwich, N.Y.: Noyes Publications; William Andrew Pub. xii, 527 p.

12. Ballester, J. and C. Dopazo, Discharge coefficient and spray angle measurements for small pressure-swirl nozzles. Atomization and sprays, 1994. 4(3).

13. Jasuja, A.K., ATOMIZATION OF CRUDE AND RESIDUAL FUEL OILS. Journal of Engineering for PowerTransactions of the Asme, 1979. 101(2): p. 250-258.

14. Rizk, N. and A. Lefebvre, Drop-size distribution characteristics of spill-return atomizers. Journal of Propulsion and Power, 1985. 1(1): p. 16-22.

15. Li, T., K. Nishida, and H. Hiroyasu, Droplet size distribution and evaporation characteristics of fuel spray by a swirl type atomizer. Fuel, 2011. 90(7): p. 2367 - 2376.

16. Wang, X.F. and A.H. Lefebvre, MEAN DROP SIZES FROM PRESSURE-SWIRL NOZZLES. Journal of Propulsion and Power, 1987. 3(1): p. 11-18.

17. LEFEBVRE, A.H. and D. NICKOLAUS, Fuel thermal stability effects on spray characteristics. Journal of Propulsion and Power, 1987. 3(6): p. 502-507.

18. Rizk, N.K. and A.H. Lefebvre, AIRBLAST ATOMIZATION - STUDIES ON DROP-SIZE DISTRIBUTION. Journal of Energy, 1982. 6(5): p. 323-327.

19. Dikshit, S., S. Channiwala, D. Kulshreshtha and K. Chaudhari, Experimental Investigations of Performance Parameters of Pressure Swirl Atomizer for Kerosene Type Fuel. 2009. ASME.

20. Moon, S., C. Bae, E.F. Abo-Serie and J. Choi, Internal and near-nozzle flow of a pressure-swirl atomizer under varied fuel temperature. Atomization and Sprays, 2007. 17(6).

21. Boyaval, S. and C. Dumouchel, Investigation on the Drop Size Distribution of SpraysProduced by a High-Pressure Swirl Injector. Measurementsand Application of the Maximum Entropy Formalism. Particle \& Particle Systems Characterization, 2001. 18(1): p. 33-49.

22. VanDerWege, B.A. and S. Hochgreb. The effect of fuel volatility on sprays from high-pressure swirl injectors. in Symposium (International) on Combustion. 1998. Elsevier.

23. Park, S.H., H.J. Kim, H.K. Suh and C.S. Lee, Atomization and spray characteristics of bioethanol and bioethanol blended gasoline fuel injected through a direct injection gasoline injector. International journal of heat and fluid flow, 2009. 30(6): p. 1183-1192.

24. Atadashi, I.M., M.K. Aroua, A.R. Abdul Aziz and N.M.N. Sulaiman, Refining technologies for the purification of crude biodiesel. Applied Energy, 2011. 88(12): p. 4239 - 4251.

25. Cooper, D., A. Yule, and J. Chinn. Experimental measurements and computational predictions of the internal flow field in a pressure swirl atomizer. in Proc. ILASS-Europe. 1999.

26. Tratnig, A. and G. Brenn, Drop size spectra in sprays from pressure-swirl atomizers. International Journal of Multiphase Flow, 2010. 36(5): p. 349-363.

27. Tipler, W. and A.W. Wilson, Combustion in Gas Turbines, in CIMAC. 1959: Paris. p. 897 - 927.

28. Chen, S., A. Lefebvre, and J. Rollbuhler, Factors influencing the circumferential liquid distribution from pressure-swirl atomizers. Journal of engineering for gas turbines and power, 1993. 115(3): p. 447-452.

29. Yule, A. and I. Widger, Swirl atomizers operating at high water pressure. International journal of mechanical sciences, 1996. 38(8): p. 981-999. 
30. Kim, S., T. Khil, D. Kim and Y. Yoon, Effect of geometric parameters on the liquid film thickness and air core formation in a swirl injector. Measurement Science and Technology, 2009. 20(1): p. 015403.

31. Lee, E.J., S.Y. Oh, H.Y. Kim, S.C. James and S.S. Yoon, Measuring air core characteristics of a pressure-swirl atomizer via a transparent acrylic nozzle at various Reynolds numbers. Experimental thermal and fluid science, 2010. 34(8): p. 1475-1483.

32. Dash, S., M. Halder, M. Peric and S. Som, Formation of air core in nozzles with tangential entry. Journal of fluids engineering, 2001. 123(4): p. 829-835.

33. Halder, M., S. Dash, and S. Som, Initiation of air core in a simplex nozzle and the effects of operating and geometrical parameters on its shape and size. Experimental thermal and fluid science, 2002. 26(8): p. 871-878.

34. Walzel, P., Liquid atomization. Journal Name: International Chemical Engineering (A Quarterly Journal of Translations from Russia, Eastern Europe and Asia); (United States); Journal Volume: 33:1, 1993: p. Medium: X; Size: Pages: 46-60.

35. Lefebvre, A.H., Atomization and sprays. Combustion,. 1989, New York: Hemisphere Pub. Corp. xi, 421 p.

36. Elkotb, M.M., N.M. Rafat, and H.M. A., The Influence of Swirl Atomizer Geometry on the Atomization Performance., in Proceedings of the first ICLASS. 1978: Tokyo. p. $109-115$.

37. Rizk, N. and A. Lefebvre, Prediction of velocity coefficient and spray cone angle for simplex swirl atomizers. International Journal of Turbo and Jet Engines, 1987. 4(1-2): p. 65-74.

38. Horvay, M. and W. Leuckel. LDA-measurements of liquid swirl flow in converging swirl chambers with tangential inlets. in 2nd International Symposium on Applications of Laser Anemometry to Fluid Mechanics. 1985.

39. Horvay, M. and W. Leuckel, Experimental and theoretical investigation of swirl nozzles for pressure-jet atomization. German chemical engineering, 1986. 9(5): p. 276-283.

40. Yule, A. and J. Chinn, The internal flow and exit conditions of pressure swirl atomizers. Atomization and Sprays, 2000. 10(2): p. 121-146.

41. Moon, S., E. Abo-Serie, and C. Bae, Liquid film thickness inside the high pressure swirl injectors: Real scale measurement and evaluation of analytical equations. Experimental Thermal and Fluid Science, 2010. 34(2): p. 113-121.

42. Nonnenmacher, S. and M. Piesche, Design of hollow cone pressure swirl nozzles to atomize Newtonian fluids. Chemical Engineering Science, 2000. 55(19): p. 4339-4348.

43. Mandal, A., M. Jog, J. Xue and A. Ibrahim, Flow of power-law fluids in simplex atomizers. International journal of heat and fluid flow, 2008. 29(5): p. 1494-1503.

44. Santolaya, J., L. Aisa, E. Calvo, I. García and L. Cerecedo, Experimental study of near-field flow structure in hollow cone pressure swirl sprays. Journal of propulsion and power, 2007. 23(2): p. 382-389.

45. Mandal, B., P. Barman, and A. Kushari. Study of Primary Atomization in a Helical Passage Pressure-Swirl Atomizer. in 19th ILASS EUROPE. 2004.

46. Chen, S., A. Lefebvre, and J. Rollbuhler, Factors influencing the effective spray cone angle of pressure-swirl atomizers. ASME Transactions Journal of Engineering Gas Turbines and Power, 1992. 114: p. 97-103.

47. Radcliffe, A., Fuel Injection, High Speed Aerodynamics and Jet Propulsion. 1960.

48. Babu, R.K., M.V. Narasimhan, and K. Karayanaswamy, Prediction of Mean Drop Size of Fuel Sprays from Swirl Spray Atomizers, in Proceedings of the second International Conference on Liquid Atomisation and Spray Systems. 1982: Madison, Wisconsin. p. 99-106.

49. Wang, X. and A. Lefebvre, Influence of ambient air pressure on pressure-swirl atomization. Atomisation Spray Technology, 1987. 3: p. 209-226.

50. Simmons, H.C. and C.F. Harding, SOME EFFECTS OF USING WATER AS A TEST FLUID IN FUEL NOZZLE SPRAY ANALYSIS. Journal of Engineering for Power-Transactions of the Asme, 1981. 103(1): p. 118-123.

51. Rizk, N. and A. Lefebvre, Spray characteristics of spill-return atomizers. Journal of Propulsion and Power, 1985. 1(3): p. 200-204.

52. Michalek, D., B. Peschke, and L. Evers, Computational design of experiments for compound fuel injector nozzles. SAE Tech Pap, 1997. Ser 971617.

53. Jedelsky, J., M. Jicha, J. Slama, and J. Otahal, Development of an Effervescent Atomizer for Industrial Burners. Energy \& Fuels, 2009. 23: p. 6121-6130.

54. Yule, A.J. and J.J. Dunkley, Atomization of Melts: For Powder Production and Spray Deposition. Oxford Series on Advanced Manufacturing (Book 11). 1984, USA: Oxford University Press. 424 pages.

55. Jaber, J.O. and S.D. Probert, Environmental-impact assessment for the proposed oil-shale integrated trigeneration plant. Applied Energy, 1999. 62(3): p. 169-209.

56. Abdolzadeh, M. and M. Ameri, Improving the effectiveness of a photovoltaic water pumping system by spraying water over the front of photovoltaic cells. Renewable Energy, 2009. 34(1): p. 91-96.

57. Chen, Q., A. Rao, and S. Samuelsen, H2 coproduction in IGCC with CCS via coal and biomass mixture using advanced technologies. Applied Energy, 2014. 118(0): p. 258-270.

58. Balat, M. and H. Balat, Recent trends in global production and utilization of bio-ethanol fuel. Applied Energy, 2009. 86(11): p. 2273-2282. 


\section{Appendix}

The SMD, the frequently used spray characteristic in mass and heat transfer studies, is reported here as a measure of atomization quality. The SMD of droplets moving through the measurement volume in a measurement position $j$ is defined using general formula [1]:

$$
D_{p q, j}=\sqrt[p-q]{\sum_{i=1}^{n_{j}} D_{i j}^{p} / \sum_{i=1}^{n_{j}} D_{i j}^{q}}
$$

where $p=3$ and $q=2$. The size spectrum of droplets generated by PS atomizer is not spatially uniform (see Figs. 6 and 7 in the main paper) so $D_{32}$ varies along the radial profile. For the sake of conciseness and comparison of results we defined an integral value of diameters $D_{32}-I D_{32}$, as a single parameter to represent globally the droplet size in the spray. Note that some authors [2] use the same term while other authors refer to this overall value as the mean diameter [3]. Calculation of the $I D_{32}$ is based on the surface area mean diameter and volume mean diameter $D_{20, j}$ and $D_{30, j}$ respectively, according Eq. (A.1) with corresponding $p$ and $q$ values, measured in axisymmetric spray, at radial positions $r_{j}$, with droplet transit frequency $f_{j}$ using PDA. Simplified estimation of $I D_{32}$ as a representation of $D_{32}$ averaged through entire radial profile reads:

$$
I D_{32}=\sum_{j=2}^{m}\left(r_{j} D_{30, j}^{3} f_{j}\right) / \sum_{j=2}^{m}\left(r_{j} D_{20, j}^{2} f_{j}\right) .
$$

For the full description of $I D_{32}$ calculation see [4] Appendix 1, which also explains simplifications and uncertainties of the method. This approach of weighting by data rate for estimation of overall $D_{32}$ was used in [5] for estimation of the global SMD. Similar calculation of overall $D_{32}$ with weighting by the cross-section area was used in [6] and [3] and previously suggested by Zaller and Klem [7] for calculation of the mean value of $D_{30}$.

The estimation of overall $D_{32}$ in PS sprays depends on the method applied for the drop size measurement [8]. For example laser diffraction droplet sizing uses an expanded laser beam passing through whole the spray. This frequently used ensemble measurement technique is a concentration-based measurement. Therefore, particle velocities are not accounted for [9] and the weighting factor $r_{j}$, which covers the variation in the sprayed area with radial distance in Eq. (A.2), is not included, as well. Results acquired using such a method would, therefore, differ from these from PDA in the same spray.

\section{References}

1. Lefebvre, A.H., Atomization and sprays. Combustion,. 1989, New York: Hemisphere Pub. Corp. xi, 421 p.

2. Jakobs, T., N. Djordjevic, S. Fleck, M. Mancini, R. Weber and T. Kolb, Gasification of high viscous slurry $R \& D$ on atomization and numerical simulation. Applied Energy, 2012. 93(0): p. 449-456.

3. Im, J.H., D. Kim, P . Han, and Y. Yoon, Self-pulsation characteristics of a gas-liquid swirl coaxial injector. Atomization and Sprays, 2009. 19(1): p. 57-74.

4. Jedelsky, J., M. Jicha, J. Slama, and J. Otahal, Development of an Effervescent Atomizer for Industrial Burners. Energy \& Fuels, 2009. 23: p. 6121-6130.

5. Tratnig, A. and G. Brenn, Drop size spectra in sprays from pressure-swirl atomizers. International Journal of Multiphase Flow, 2010. 36(5): p. 349-363.

6. Otahal, J., J. Jedelsky, J. Fiser and M. Jicha, Efficiency of the pressure and effervescent atomization, in 21 Annual Conference on Liquid Atomization and Spray Systems. 2007: Mugla, Turkey. p. 76-79.

7. Zaller, M. and M. Klem, Shear Coaxial Injector Spray Characterization, Liquid Rocket Engine Combustion Instability, in AIAA, Cambridge Massachusetts. 1995. p. 191-213.

8. Fdida, N., J.B. Blaisot, A. Floch and D. Dechaume, DROP-SIZE MEASUREMENT TECHNIQUES APPLIED TO GASOLINE SPRAYS. Atomization and Sprays, 2010. 20(2): p. 141-162.

9. Robart, D., S. Breuer, W. Reckers and R. Kneer, Assessment of pulsed gasoline fuel sprays by means of qualitative and quantitative laser-based diagnostic methods. Particle \& Particle Systems Characterization, 2001. 18(4): p. 179-189. 